\title{
Discussion of Goguryeo National Costume Structure and Category
}

\author{
Jinsong Li \\ College of Fine Arts, Tonghua Normal University, Tonghua 134002, China
}

Keywords: Goguryeo, National costume, Shape and structure, Category

\begin{abstract}
Goguryeo clothing research is an important part of the study of social culture of Goguryeo, which is conducive to the comprehensive understanding of Goguryeo's production, life, and social development. The article will do the research of Goguryeo national costume style and categories through the three aspects as flowing : Goguryeo national costume style and categories, identity category reflected by the costume style and categories, regional differences of the costume style and categories and the evolution history .
\end{abstract}

\section{Goguryeo National Costume Structure and Category}

At current stage, our intuitive understanding and quantitative analysis of Goguryeo national costume mainly comes from the related apparel information of the Goguryeo tomb murals. Through investigation of these physical material and the research results of the relevant archaeologists and scholars, Goguryeo dress can be divided into the following four categories via style and category: Head dress, body clothes, foot wear and accessories.

\section{Head dress}

The head dress means crown, towel, hat, scarf and related accessories worn on head in ancient China. There is wide variety of head dress in Goguryeo, according to documentary records, there are several common types, such as Ze(ancient scarf),Shefeng( like crown cap), crown, head cloth. It is worth noting that in that society, there are different provisions for the head dress for people of different grades and different levels . Emperor Liang Yudi once said about famous ancient painting

《Zhi Gong Tu》: "The noble wears crown cap, gold and silver ornaments as decoration on the scarf; poor people wears Shefeng and gold earrings " [1] In ancient times, the noble class usually wear the crown scarf, and leaving all the hair outside the scarf, Ze means the head cloth that covers on the head to tie the hair. Shefeng is a kind of unique head dress to prevent the crown falling off in Goguryeo era, the using of Shefeng has been run through different rule region and every historical period of Goguryeo, it is the most common form of head dress at that time. [2] There is another very common head dress in Goguryeo era which is named scarf, usually worn by male people, the scarf is in black color, we can see many male hunter wear the black scarf from the tomb murals in Goguryeo era.

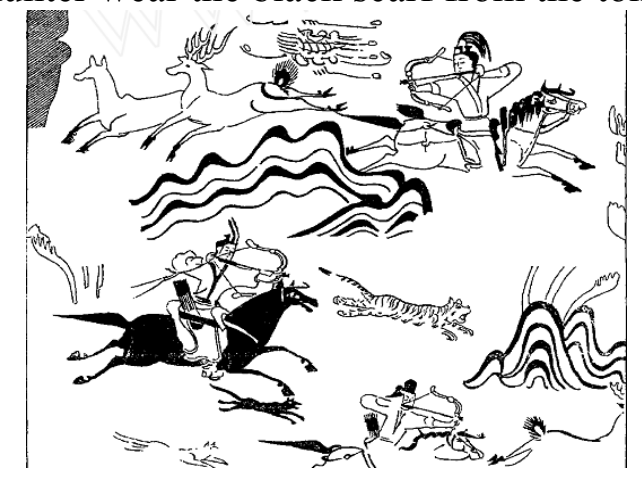

Fig. 1 Hunting murals inside tomb (line drawing) 


\section{Body clothing}

There is various kinds of body clothing during Goguryeo era, generally speaking it is similar to the Shangyixiashang style (blouse plus under dress) in central plains region of China at that time: the dress of the upper part of the body usually is called $\mathrm{Yi}$, the dress of the lower part of the body is called Shang, the most common category of the body clothing including: Ru (cutty sark), half sleeve and gown. Shang can be categorized as trousers and dressing etc. Ru as a very common cutty sark at that time, the length recorded in the literature is usually only reach to the hips, but the actual investigation from many ancient tomb murals we can see that $\mathrm{Ru}$ worn by aristocratic women is usually longer in length, which will cover the thighs. Half sleeve is a kind of cutty sark worn by the women at that time, and it is not very common at that time, When it comes to the Han Dynasty, the half sleeve is becoming more popular, and from that time onwards it has become the women's normal wearing.

Generally the robe refers to underwear with cotton, it is usually worn inside, only the women wearing it during the Goguryeo period, and it can be regarded as a long robe from the length aspect. The characteristics of the robe is very obvious, most of the robe are in the form of cross collar, the length can been reached to the lower leg.

Qiongku is the clothes worn under the lower part of the body which is the common wearing during the Goguryeo period, Qiongku is a kind of Xiashang which has the front and back crotch, it is what now called as trousers, both men and women wore this kind of pants at that time. But it is worth noting that the width of the pants becomes a symbol of the wearer's identity levels, noble will wear the more loose trousers, while waiters and civilians can only wear more narrow leg pants . Skirt as a traditional costume of Goguryeo woman, men usually don't wear it. there were two main styles of the dress at that time, one is worn inside the long robe, only the lower part of the dressing can be seen from outside, another one is the skirt collocation with jacket, the length this kind of skirt is usually only can reach to the crotch.

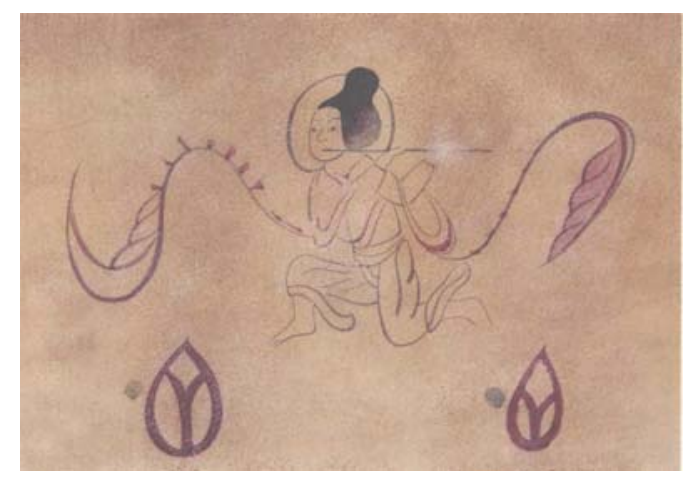

Fig. 2 Flying Apsaras of Changchun NO 1 tomb murals

\section{Foot wear}

We have some understanding of the foot wear through the relevant literature records and murals, foot wear can be divided into the following three types in Goguryeo era:_Lv (shoes),_boots, nail shoes. Lv (shoes) with its shoe - tops tilt in the opposite direction, which is the most striking feature of it, the sole and welt is decorated with yellow line. The boots and Lv (shoes) have some common features of the style and structure, both are showing a pointed shoe shape, and upturned shoe - tops, the difference is that the cylinders of boots are much higher than those of $\operatorname{Lv}$ ( shoes). Besides that, nail shoes is a kind of foot wear specially worn by Goguryeo in Winter, they used to wear it in the snow in winter. There is no instep of nail shoes, only copper hobnail pinned on the sole with upturned shoe - tops. Nail shoes is especially suitable for walking in the deep mountains and forests in the ice and snow weather, it is a very practical antiskid shoes.

\section{Decorations}

Goguryeo inhabited area is rich in gold and silver. According to the relevant facts, Goguryeo has mastered the technology of mining of gold and silver and manufacturing of gold and silver utensils . 
It is because of the rich mineral, Goguryeo has the customs of wearing gold and silver ornaments since ancient times, they often decorated crown cap and dress with gold and silver ornaments . So far, China has unearthed a large number of gold and silver ornaments of Goguryeo era, including the earrings, bracelets, rings and other ornaments, through research and analysis we can know the most common one is the pendant with many styles.

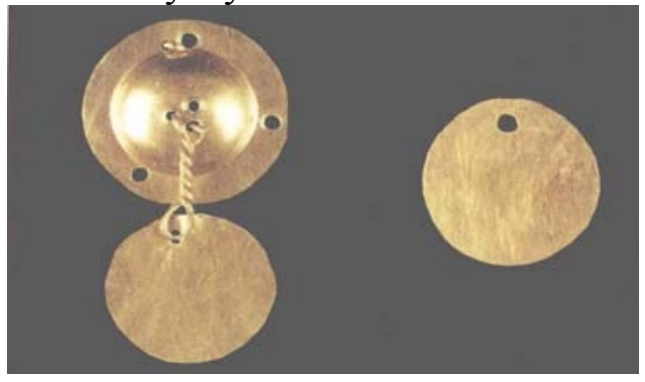

Fig. 3 The unearthed tomb No. 992 Yu Shan Buyao ornaments

\section{The identity reflected by different style and categories of Goguryeo dress}

Goguryeo society can be said to be hierarchical at that time, which is reflected intuitively from Goguryeo wearing. There is obvious distinction of People of different identities and social classes, no matter it is in the style of dress, decorations, and color, etc. The author will concretely elaborate the difference of the style and category of clothing showing by different identities from following three aspect: Goguryeo official clothes, civilian clothes and military dress.

\section{Goguryeo official clothes}

The king of Goguryeo

The material, style and color of the king's dress is a label of supremacy identity of the king. Chapter 149 of 《collected biographies 》 on volume 199 of 《Ancient Tang》 once recorded:" Clothes and ornament, only the King can use the bright color, crown hat made by white silk with small white leather belt, all decorated with gold and silver...." [3] We can see from it that only the King have the right of "decorated with gold and silver"(all decorated with gold and silver), the marquis and minister's dress can only be partly decorated with gold and silver.

Dajia

Dajia is the chief of Yi tribe which is the larger tribe among the five tribe in Goguryeo, and it is the higher bureaucratic aristocracy in Goguryeo society. Firstly, the style and the color of head wear of Dajia is different from civilian class.[6]On the other hand, Dajia usually wear decorations with gold and silver.

Xiaojia

Xiaojia is the common name of those officer with low position. The characteristics in the early stage of Xiaojia is that they usually wear the Shefeng on the head, Ku Zhe ( like the traditional clothing of northern nomadic people) on the body and ankle boot on the foot. Later, with more and more common use of Shefeng among civilian, in order to distinguish with the common people, Xiaojia usually plug in the bird feather on Shefeng to show their identity as officials.

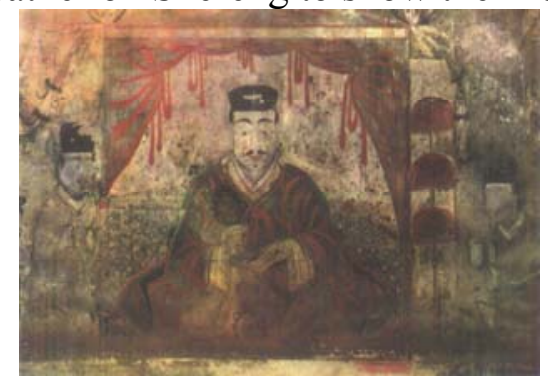

Fig. 4 Portrait of the man on North Korea murals 


\section{Goguryeo civilian clothing}

\section{Men's dress}

Goguryeo civilian clothing of men is usually with the style of upper body with short jacket and lower body with Qiongku(like trouser), the short jacket worn by the upper part of the body is usually cross collar with simple sleeves, the waist is tight up with ribbon. the pants of the men's are usually very loose and the trousers is tied up, wearing the black boots with toe cap upturned, the boot bottom is white. Civilian men's dress is generally in the color of red, orange, green, black, blue, white and other colors, the clothing may be decorated with geometric patterns or dot stripes, and wearing the black scarf on the head, which is very typical clothing of civilian men in Goguryeo at that time.

Women's dress

There are three kinds of most common collocation of Goguryeo civilian women's dress : the first collocation is the upper robe and lower pleated skirt, robes in this collocation are usually relatively long, pleated skirt inside can only leaving the lower part outside. The second kinds of collocation is that the short jacket with trousers, this collocation has some certain similarity with men's clothing, general speaking, the bottom labor class women will wear this kind of dress. The third collocation is long jacket with pleated skirt, the skirt will be much longer in this kind of collocation, it is long enough to touch the ground, often foot wear (shoes) cannot been seen from outside.

\section{Dance Costume}

There is a very detailed records of the characteristics of Goguryeo dance costumes in historical books:"Korea musician, with purple crown hat, decorated with feather, yellow big sleeve, purple belt, loose trousers, red boots, colored sash rope. The dancers, four people with bun shaped like a mallet on the back side of head, purple red daubed on the forehead, decorated with gold pendant; two people with yellow dressing, red trousers, extremely long sleeve, black boots; dancing together." [1] By this description the distinctive features of the music dancer's dress is very clearly showing in front of us, it can also be seen that the dress style and color of musician and dancers of that era is very sophisticated.

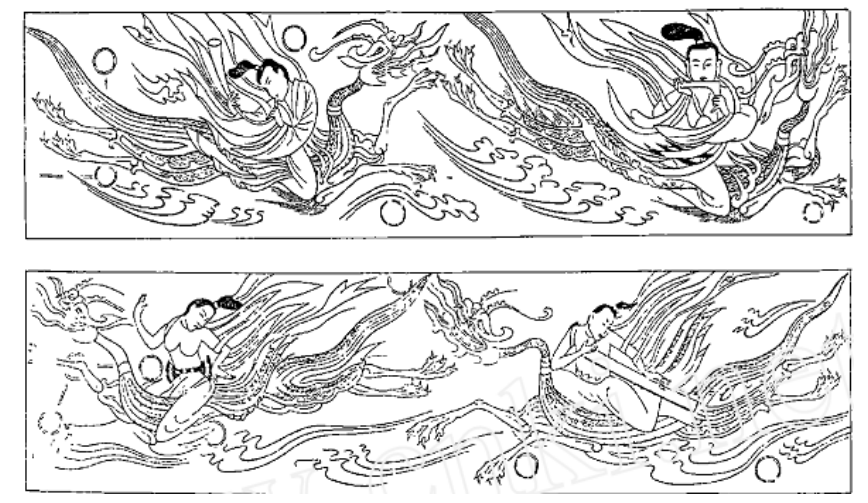

Monk dress

Fig.5 Jiyue Fairy with Lapras in tomb No.5

Since Buddhism was introduction to Goguryeo in fourth Century, it had become state religion of Goguryeo, and it was spreading quickly. It is regrettable that is very rare to see the literature of Goguryeo monk's dress and the related tomb murals now, but we can have some general understanding about monk's dress of that time only with these limited material objects, one thing can been curtained is that the monks will generally put red striped cassock outside with black robe inside.

\section{Goguryeo military apparel}

\section{Military uniform on the Goguryeo tomb murals}

There is related description about the military uniform on the Goguryeo tomb murals . As a warlike nation, they are very good at horsemanship and archery in the mountains, therefore Goguryeo military as a very strong troop in northern part is very good at both defend and attack, It can be imagined that it is very well-trained troops. From the military dress describe by the Goguryeo tomb murals, we can see that the armor has a very distinctive feature. Goguryeo military helmet is 
decorated with double horn, there is high tilt collar on the armor neck, the armor of the lower part of the body is very similar to the pants today, foot usually wear the nail shoes. By the military dress depicted in the murals, people have been able to feel the national martial spirit of Goguryeo, at the same time, but it embodies the practicality design of Goguryeo armor.

The Goguryeo military apparel unearthed from ruins and tombs

Some scattered pieces of armor of Goguryeo military clothing has been unearthed from many sites and tombs, from the archaeological objects unearthed we can see that generally these objects and the Goguryeo military clothing style depicted by Goguryeo tomb murals are basically the same. A large pieces of armors unearthed are in the shape of rectangular, the edge of each piece of armor has been made into slow round shape. The iron armor sheet unearthed also have a larger difference due to region difference, but overall these iron armor sheets are quite consistent in shape and related features. Among the numerous unearthed objects, no matter the iron armor sheets, nail shoes or copper spikes commonly seen from the military dress, their style and characteristics are very close to characteristics described by the Goguryeo tomb murals.

\section{Regional differences, evolution and change of Goguryeo national costume style and category}

\section{Differences of Goguryeo national costume between Ji'an and Pyongyang}

Regional difference of Goguryeo national costume is the most obvious in Ji'an and Pyongyang these two regions, differences can be reflected in the following aspects: Firstly, the difference of head wear is mainly reflected in the Ze(turban) and Shefeng( like crown cap), as the most common male head dress, The man in Jian region usually decorates a bird feather on the Ze(turban) and Shefeng( like crown cap) to show their identity. There is a big difference in the Pyongyang area, the head wear of man of the upper class in Pyongyang is very similar to the style of Central Plains Dynasty at that time. Secondly, there are also distinct differences of the body clothes in the two regions, Ji'an inherited the implicit fashion style of Goguryeo, usually as the style of Shangyixiashang like upper jacket with lower trousers. There is a difference in the Pyongyang area, its body clothing is also consistent with the Central Plains Dynasty, which is named Shegyi(Han style clothes)that joint the upper and lower clothes together.Thirdly, for the foot wear, due to the cold weather in the north, people in Ji'an area usually wear nail shoes that is thermal and skid proof, on the one hand ,Pyongyang area is located on the plain area, there is no need to wear like that, on the other hand, due to the culture influence of the central plains region, the foot wear is consistent with the fashion of the Central Plains.

\section{The historical evolution and change of Goguryeo national dress}

\section{Regime's initial construction period}

During this period, Goguryeo as a nation in the primary development stage and a relatively small ethnic group, is still in a relatively closed status as for culture. Thus in this period, Goguryeo inherent national costume had not been affected by the Central Plains region, the dress is not so complicated in style and category.

Eastern Jin Dynasty, Northern and Southern Dynasties

During this period, the ethnic costume of Goguryeo with the distinctive characteristics is coexistence of mainstream dress of Yuelang Jin Dynasty. because of the war in Central Plains region and the frequent replacement of the regime during this period, Goguryeo also took advantage of the weak point in Central Plains region and gradually got rid of the control of the Central Plains Dynasty. During this period, a large number of northern residents migrated to the South because of the war. Inevitably there would be national culture and customs collision of north and south regions, thus that will lead to dress culture communication, which is the direct cause why the Goguryeo dress is quite complex during this period.

Sui and Tang dynasties 
The Central Plains region of the Sui and Tang Dynasties got the political unification again, therefore Chinese culture was very strong and Goguryeo clothing was also deeply influenced by it, Gaogouli clothing has been gradually formed its own mature and stable characteristics during that period, the ruling class gradually accepted the dress system of Central Plains and made a distinction among canonicals, court dress informal dress.

\section{References}

[1] ( The Western Han Dynasty) Sima Qian. Shi Ji(Historical Records), Peking: Zhonghua publishing house, 2010

[2] (Tang Dynasty) Linghu Defen. Zhou Shu· Koryo biography. Zhonghua publishing house, 2003

[3] ( The Five Dynasties)Liu Xu,, Book of Ancient Dynasty, first edition, 1975

[4] Three Kingdoms, Peking: Zhonghua publishing house, 2007

[5] The Northern Qi Dynasty. Wei shou. Wei shu, Peking: Zhonghua publishing house, 2008

[6] Southern Song Dynasty, Fan Ye. History of the Later Han Dynasty ; Wan Juan Publishing Company, 2009

[7] Geng Tiehua. Goguryeo nationality origin and national amalgamation, Journal of Social Science Periodicals, 2010, 01

[8] $\mathrm{Xu}$ Dongliang, See the origin of Goguryeo culture from the founding legend, Journal of Tonghua Normal University, Periodicals, 2010,01 